\title{
PHOTOLUMINESCENCE OF ANODIC OXIDE FILMS ON ALUMINIUM
}

\author{
SAKAE TAJIMA, NOBUYOSHI BABA, KENICHI SHIMIZU and ISSEI MIZUKI \\ Department of Industrial Chemistry, Tokyo City University, Fukazawa, Setagaya-ku, Tokyo, 158, Japan
}

(Received January 5, 1976; in final form May 5, 1976)

\begin{abstract}
A wide variety of anodic oxide films were investigated from the photoluminescent point of view. It was found that the phenomenon of photoluminescence appears only on the films anodically formed in organic acids instead of inorganic acids. In particular, thick oxalic acid films formed in low electrolyte concentration, with high current densities on high purity aluminium, gave intense photoluminescence. The luminescent centres were presumed to be the carboxylate ions which had been incorporated in the films during anodisation.
\end{abstract}

\section{INTRODUCTION}

It is well known that anodic oxide films on aluminium exhibit many interesting properties such as rectifying action, ${ }^{1}$ photoconduction, ${ }^{2}$ photo-voltaic effect, ${ }^{3}$ etc. The phenomenon of luminescence is also one of these properties, and occurs in two types: (a) Electroluminescence $(\mathrm{EL})^{4-6}$ which is seen during anodisation of aluminium in certain electrolytes such as oxalic acid and ammonium borate; and (b) Photoluminescence $(\mathrm{PL})^{7-13}$ which is seen with anodic oxide films formed in oxalic acid, when irradiated by ultra-violet light.

Although many studies have been made of the photoluminescence of anodic oxide films on aluminium, all of these are concerned only with anodic oxide films formed in the solution of oxalic acid. Among these studies, the mechanism of photoluminescence and nature of luminescent centres have been discussed by Ruziewicz ${ }^{9}$ for the former and by Tseitina ${ }^{12}$ for the latter. However, as is well known, anodic oxide films can be formed in a variety of electrolytes other than oxalic acid, and we found that some films show photoluminescence while others do not. Therefore, the theories proposed by Ruziewicz and by Tseitina may not be sufficient for complete understanding of the phenomena of photoluminescence of anodic oxide films on aluminium in general.

In this paper, anodic oxide films formed in a wide variety of electrolytes are investigated from the photoluminescent point of view, and the nature of luminescent centres is discussed on the basis of experimental results.

\section{EXPERIMENTS}

Anodic oxidation. Aluminium specimens of 99.999\% (Superraffinal, Alusuisse), $99.99 \%$ and $99.8 \%$ purity, $0.05 \mathrm{~cm}$ thick, $2.5 \mathrm{~cm}$ wide, $4 \mathrm{~cm}$ long were degreased with acetone and then rinsed with distilled water. Anodising conditions for film formation are greatly affected by the electrolyte used; in the case of formic acid solution, for example, anodic oxide films could not be formed below a concentration of about $60 \%$ (w/o). Anodic oxide films were formed with anodising conditions shown in Table 1.

Measurement of PL intensity. The excitation beam was obtained from a Toshiba $\mathrm{H}-400 \mathrm{P}$ mercury lamp

TABLE I

Anodising electrolytes and conditions of electrolysis

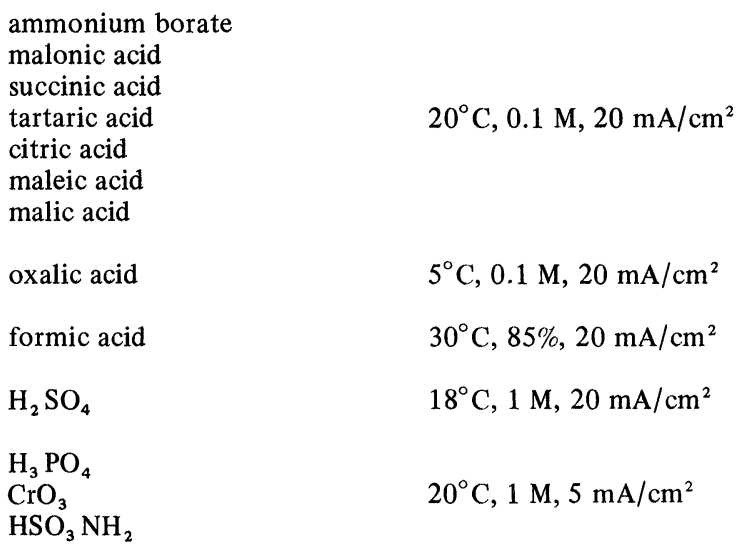


using a Toshiba UV-D1C filter. Samples were excited in dark box, and PL intensity was measured with a Toshiba MS-9S photomultiplier through a Toshiba VY-42 filter.

Measurement of film thickness. The film thickness was measured by a Darmitron Thickness Tester (Model D-2E1), the measuring range of which is 0 to $100 \mu \mathrm{m}$ with error of $\pm 0.25 \mu \mathrm{m}$.

Emission spectra. Emission spectra of the films were measured with a Hitachi MPF-2A fluorescence spectrometer with $365 \mathrm{~nm}$ excitation.

Ultraviolet-visible spectra. Ultraviolet-visible transmittance spectra of anodic oxide films stripped from the substrate aluminium were measured with a Shimadzu UV-200 spectrophotometer relative to the blank.

Infrared spectra. Infrared transmittance spectra of anodic oxide films stripped from the substrate aluminium were measured by a JASCO IPA-1 spectrophotometer.

\section{RESULTS AND DISCUSSION}

\subsection{Effect of Anodising Conditions on Photoluminscence}

Effect of the electrolyte. Anodic oxide films were classified from the photoluminescent point of view in Figure 1. Photoluminescence was seen only with anodic oxide films formed in organic acid solutions, accompanied by yellowish after-glow. It is well known that two different types of anodic oxide films, viz., barrier-type and porous-type, may be formed when aluminium is made the anode in various electrolytes. ${ }^{14}$ The nature of the electrolyte mainly determines which type appears. Among organic electrolytes referred to in Figure 1, tartaric, citric, succinic, maleic, and malic acid solutions, as well as ammonium borate solution, are usually regarded as barrier-forming electrolytes. It has been generally accepted that the maximum film thickness attainable for barrier-type films is restricted by the so-called breakdown voltage of the oxide $(14 \AA \times \mathrm{V})$ and, if anodisation is continued galvanostatically after the breakdown voltage is attained, the formation voltage remains nearly constant accompanied by scintillation and the film grows only slightly by repeating breakdown and repair processes. Under the anodising condition we employed, it was found that this was

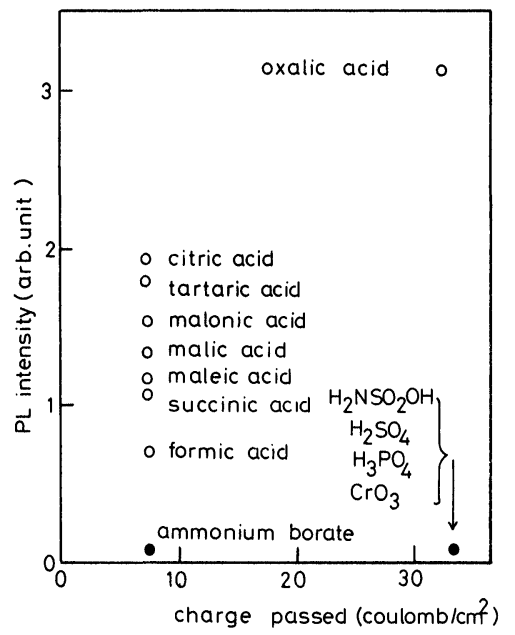

FIGURE 1 PL intensity and forming electroly tes: Inorganic acid films give no PL, while organic acid, particularly oxalic acid give intense PL.

true for ammonium borate and succinic acid. When the so-called final voltage was attained in the case of tartaric, citric, and malic acids, the scintillation and gas evolution were seen only slightly, the film thickness increased non-uniformly over the entire anode surface and the voltage also remained nearly constant even with further galvanostatic anodisation. The film thickness formed by 8 coulombs $/ \mathrm{cm}^{2}$ was 4 to $2 \mu \mathrm{m}$ for tartaric acid film, 5 to $2 \mu \mathrm{m}$ for citric acid film, and $3 \mu \mathrm{m}$ for malic acid film. Therefore, it seems that such films may have intermediate properties between pure barrier films and porous duplex type films. Scintillation was not seen in galvanostatic anodisation in maleic acid after the formation voltage had reached a final voltage, while gas evolution was copious. So the film thickness

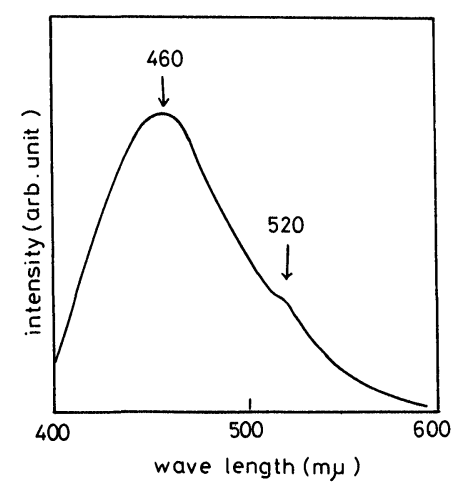

FIGURE 2 Emission spectra of PL of oxalic acid film irradiated by UV. 
attained by 8 coulombs $/ \mathrm{cm}^{2}$ may probably be less than $1 \mu \mathrm{m}$.

The film thickness was found to be a factor which determines PL intensity, and a thicker film favours PL intensity. Oxalic acid is the electrolyte which produces a typical porous film and films thicker than $30 \mu \mathrm{m}$ can easily be obtained. Thus oxalic acid is the most appropriate electrolyte for getting films which show intense photoluminescence.

The emission spectrum typical of the films formed in organic acid solution referred to above is shown in Figure 2. The two emission peaks appear near $460 \mathrm{~nm}$ and $520 \mathrm{~nm}$.

Effect of the impurities in aluminium. Aluminium is usually contaminated by small amounts of iron, copper, and silicon. Therefore, anodic oxide films always contain these impurities regardless of the forming electrolytes used. The effect of these impurities on the photoluminescent properties of the films were examined using aluminium of $99.999 \%$, $99.99 \%$, and $99.8 \%$ purity. The contents of iron, copper, and silicon are listed in Table 2 for each aluminium.

The variation of the impurity concentrations in the film did not affect the characteristics of emission spectra. When the film thickness was $3 \mu \mathrm{m}$ the difference in the intensity of the natural colour among respective films was insignificant, and PL intensity was independent of the aluminium used. However, when the film thickness exceeded $3 \mu \mathrm{m}$ and the difference of the colour among the respective films became significant, the difference in PL intensity increased correspondingly.

The oxide films anodically formed in oxalic acid exhibit yellowish-brown colour. The mechanism of colouring is not yet clear, but its intensity is partly dependent upon the impurity concentrations in the substrate $\mathrm{Al}$, upon current densities applied and the film thickness. Aluminium of $99.99 \%, 99.999 \%$ gave slightly coloured films, while that of $99.8 \%$ gave deep colour shades. The ultraviolet-visible transmittance spectra of these films were compared at the thickness

TABLE 2

Chemical composition of aluminium specimens

\begin{tabular}{llllllll}
\hline & $\mathrm{Si}$ & $\mathrm{Fe}$ & $\mathrm{Cu}$ & $\mathrm{Mn}$ & $\mathrm{Zn}$ & $\mathrm{Ti}$ & $\mathrm{Mg}$ \\
\hline $99.8 \% \mathrm{Al}$ & 0.07 & 0.18 & 0.01 & $\mathrm{Tr}$ & $\mathrm{Tr}$ & $\mathrm{Tr}$ & 0.01 \\
$99.99 \% \mathrm{Al}$ & 0.003 & 0.002 & 0.003 & & - & \\
$99.999 \% \mathrm{Al}$ & 0.0002 & 0.00026 & 0.00025 & & - & \\
\hline
\end{tabular}

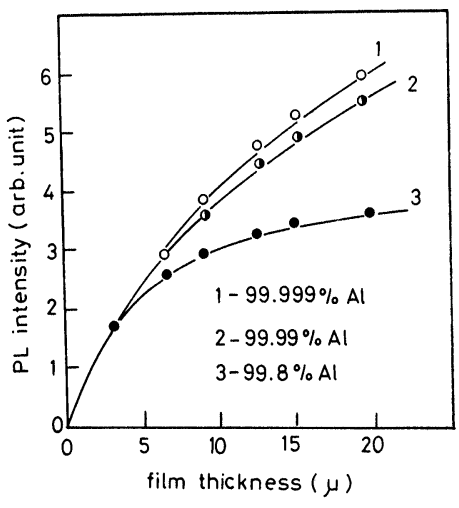

FIGURE 3 The variation of PL intensity of anodic oxide films formed on $\mathrm{Al}$ of different purity; $5^{\circ} \mathrm{C}, 0.1 \mathrm{M}$ oxalic acid, $20 \mathrm{~mA} / \mathrm{cm}^{2}$.

of $20 \mu \mathrm{m}$, and it was found that the deepening of the colour caused the decay of transmittance of ultraviolet and visible lights through the film over the whole range of wave length. This suggests that the deeper is the colour, the larger is the amount of excitation beam absorbed superficially and the contribution of the inner layer to the PL intensity is accordingly smaller resulting in the decay of the PL intensity. This may be the reason why PL intensity of the $99.999 \%$ aluminium is greatest, why the difference in the PL intensity among respective films increases correspondingly as the difference in the deepness of the colour becomes noticeable, and why 99.8\% $\mathrm{Al}$ films show marked tendency of the saturation of the PL intensity as seen in the curve 3 of Figure 3.

Effect of the formation current density. The effect of the formation current density on PL intensity of

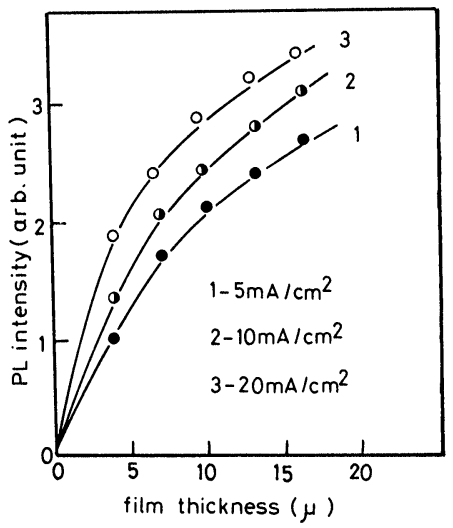

FIGURE 4 The variation of PL intensity with formation current; $5^{\circ} \mathrm{C}, 0.1 \mathrm{M}$ oxalic acid, $99.8 \% \mathrm{Al}$. 
the films of $99.8 \% \mathrm{Al}$ is shown in Figure 4. The variation of the formation current density gave no changes in the characteristics of emission spectra. As is clear from Figure 4, the difference in PL intensity due to current densities applied is constant and already determined at the thin film thickness of $3 \mu \mathrm{m}$. Further increase in thickness does not affect the difference in PL intensity among respective films. The higher current density favours PL intensity on the one hand, but, on the other hand, gives deeper colour shades on the film which tend to disturb the transmittance of excitation beam, thus resulting in the decay of the PL intensity. The approximately constant difference observed in PL intensity in the case of films thicker than $3 \mu \mathrm{m}$ may presumably be due to these two counteracting effects of the formation current.

Effect of the concentration of electrolytes. The effect of the electrolyte concentration on PL intensity of the films of $99.8 \% \mathrm{Al}$ is shown in Figure 5. Variation of the electrolyte concentration gave no changes in the characteristics of emission spectra or in the intensity of the colour. The lower electrolyte concentration favours PL intensity. The difference in PL intensity due to the variation of the electrolyte concentration is constant and determined at the film thickness as thin as $3 \mu \mathrm{m}$. Further increase in thickness produces no change in this relation.

\subsection{Luminescent Centres of Anodic Oxide Films}

The results presented above are suggestive of the nature of the luminescent centres of anodic oxide films on aluminium. The photoluminescence is seen only with anodic oxide films formed in organic acids,

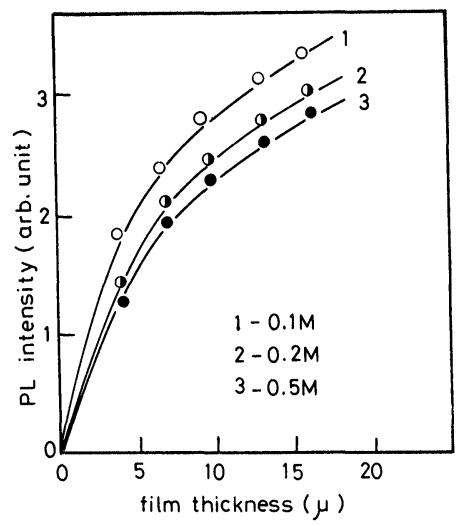

FIGURE 5 Effect of oxalic acid concentration on PL intensity; $5^{\circ} \mathrm{C}, 20 \mathrm{~mA} / \mathrm{cm}^{2}, 99.8 \% \mathrm{Al}$. which is contrary to the suggestion that the photoluminescence may be caused either by lattice defects (interstitial $\mathrm{Al}^{+++}$ion, oxygen vacancy, etc.), by impurities or by both, since these may be present in anodic oxide films formed in either organic or inorganic acid. It is well known that in the case of luminescence of $\mathrm{ZnS}$, for example, a small amount of $\mathrm{Cu}$ or $\mathrm{Fe}$ is very influential upon luminescence. The former gives a very favourable effect, while the latter a reverse effect ${ }^{15}$. The fact that the variation in oxalic acid films of the impurity concentrations such as $\mathrm{Fe}, \mathrm{Si}$, and $\mathrm{Cu}$ which come from the substrate aluminium, gave no changes in those photoluminescent properties, such as intensity (at $3 \mu \mathrm{m}$ thickness) and spectrum, also suggests that the photoluminescence is not caused by these impurities.

Recently, Tseitina and Eidel'berg ${ }^{12}$ have investigated the luminescence and its temperature dependence of $\mathrm{Al}(\mathrm{OH})_{3}, \gamma-\mathrm{Al}_{2} \mathrm{O}_{3}$, and of anodic oxide films formed in oxalic acid in order to study the nature of the luminescent centres. They stated that the photoluminescence is connected with adsorption of $\mathrm{H}_{2} \mathrm{O}$ at active centres (defects) on the oxide film surface. However, their study is concerned only with anodic oxide films formed in oxalic acid, and the experimental observations shown above, that $\mathrm{PL}$ is not observed in inorganic acid films, and the current density and electrolyte concentration effects on the PL intensity, can not be explained on the basis of their assumption.

The incorporation of anions into anodic oxide films has been reported by many workers. For pore-forming electrolytes, the incorporation is generally high; up to $17 \%$ has been reported for $\mathrm{H}_{2} \mathrm{SO}_{4}$ films by Pullen, ${ }^{14,16}$ Philips, ${ }^{17}$ and Mason $^{18} ; 3 \%$ has been reported for oxalic acid films by Pullen. ${ }^{16,17}$ Mason $^{18}$ also reported that the incorporation was greater at higher current density during film formation. These facts and our experimental observations seem to be quite favourable for the hypothesis that the photoluminescence may be caused by the organic materials incorporated into the film during anodization.

Figure 6 shows the infrared transmittance spectrum of a $\mathrm{H}_{2} \mathrm{SO}_{4}$ film (dotted line) and a typical spectrum of the films formed in organic acids. The absorption at $3400 \mathrm{~cm}^{-1}$ seen by both is at the position corresponding to the stretching mode of the $\mathrm{O}-\mathrm{H}$ bond in the bound water. The double absorption band with peaks near $1600 \mathrm{~cm}^{-1}$ and $1400 \mathrm{~cm}^{-1}$ seen by the latter are typical of absorption arising from the resonance between the 


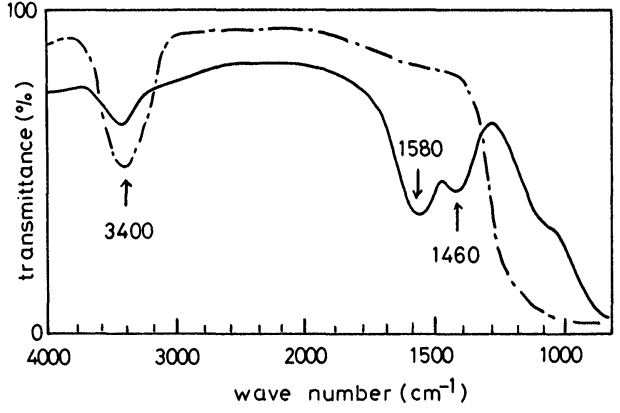

FIGURE 6 Infrared transmittance spectra of sulphuric acid (dotted line) and oxalic acid films.

$\mathrm{C}-\mathrm{O}$ bonds in the carboxylate ion structure, ${ }^{19}$ namely, the organic materials in organic acid films are present in the form of carboxylate ion. This indicates the presence of formate, oxalate, tartarate, citrate, etc. in respective films, which may be the luminescent centres of anodic oxide films on aluminium.

Further investigation into the incorporation mechanism of these carboxylate ions in anodic oxide films, i.e., the investigation of the behaviour of organic anions during film formation is needed to understand their bond structure in anodic oxide films. However, it may be reasonable to consider that the bond structure of carboxylate group in anodic oxide films is nearly the same as that of formate on alumina surface which is intermediately formed by the reaction of formic acid with catalytic alumina obeying the following reaction scheme. ${ }^{20}$

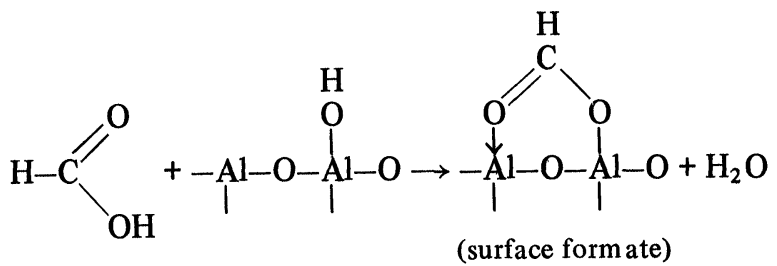

Anodic oxide films are usually amorphous ${ }^{21}$ and contain an appreciable amount of water in the form of hydroxide or hydratred alumina $(\mathrm{AlO} . \mathrm{OH})$ or both. ${ }^{22}$ Similarly the carboxylate ion is bonded with the film as shown above and presumed to exist interstitially in the three dimensional and amorphous network structure, interacting with $\mathrm{OH}$ group from bound water or with the substrate alumina.

\section{ACKNOWLEDGEMENT}

Thanks are due to Prof. K. Honda and Dr. M. Sukigara, Tokyo University, for spectroscopic measurement and to Light Metal Educational Foundations (Keikinzoku Shogakukai, Osaka) for the financial support.

\section{REFERENCES}

1. P. F. Schmidt, J. Electrochem. Soc., 8, 661 (1960).

2. W. Ch. van Geel, C. A. Pistorius, and P. Winkel, Philips Res. Rep., 13, 265 (1958).

3. K. Wolshendorf, J. Appl. Phys., 41, 5350 (1970).

4. F. Braun, Ann. Physik. u. Chemie (neue Folge), 65, 361 (1898).

5. A. Guntherschultze, Ann. d. Physik, 21, 929 (1906).

6. H. F. Ivey: in Electroluminescence and Related Effects, p. 161. Academic Press, New York (1963).

7. Z. Ruziewicz, Bull. Acad. Polon. Sci., 4, 537 (1956)

8. Z. Ruziewicz, Bull. Acad. Polon. Sci., 8, 661 (1960).

9. Z. Ruziewicz, Bull. Acad. Polon. Sci., 8, 667 (1960).

10. M. I. Eidel'berg, T. Z. Tseitina, Izv. Vyssh. Ucheb. Zavd. Fiz., 13(2), 133 (1970)

11. M. I. Eidel'berg, T. Z. Tseitina, Zh. Prikl. Spectrosk., 10(3), 521 (1969).

12. T. Z. Tseitina, M. I. Eidel'berg, Izv. Vyssh. Ucheb. Zavd., Fiz., 14(11), 142 (1971).

13. V. V. Minkoh, R. G. Molchanova, Zh. Prikl. Spectrosk., 15(4), 741 (1971).

14. S. Tajima, "Anodic oxidation of aluminum", in Advances in Corrosion Science and Technology (Fontana and Staehle, ed., Plenum Press, New York., 1970); S. Tajima, N. Baba, T. Mori and M. Shimura, Proc. Intern. Symposium on Anodizing (Birmingham, 1967), Aluminium Federation, London (1967), pp. 37-42.

15. S. Makishima, Bussei Butsurigaku Koza, 9, 133-230 (1958), Kyoritsu Shuppan, Tokyo.

16. N. D. Pullen, J. Electrodepositors' Tech. Soc., 15, 69 (1939).

17. H. W. Philips, Symposium on Properties of Metallic Surface, Institute of Metals, Monograph 13, pp. 237-252, 1953.

18. R. G. Mason, J. Electrochem. Soc., 102, 671 (1955).

19. J. C. Banter, J. Electrochem. Soc., 114, 508 (1967).

20. K. Hirota, K. Fueki, K. Shindo, and Y. Nakai, Bull. Chem. Soc. Japan, 32, 1261 (1959).

21. R. W. Franklin, Conference on Anodizing Aluminium, Nottingham, 1961, Aluminium Development Association.

22. J. D. Edwards and F. Keller, Trans. Electrochem. Soc., 79, 135 (1941). 

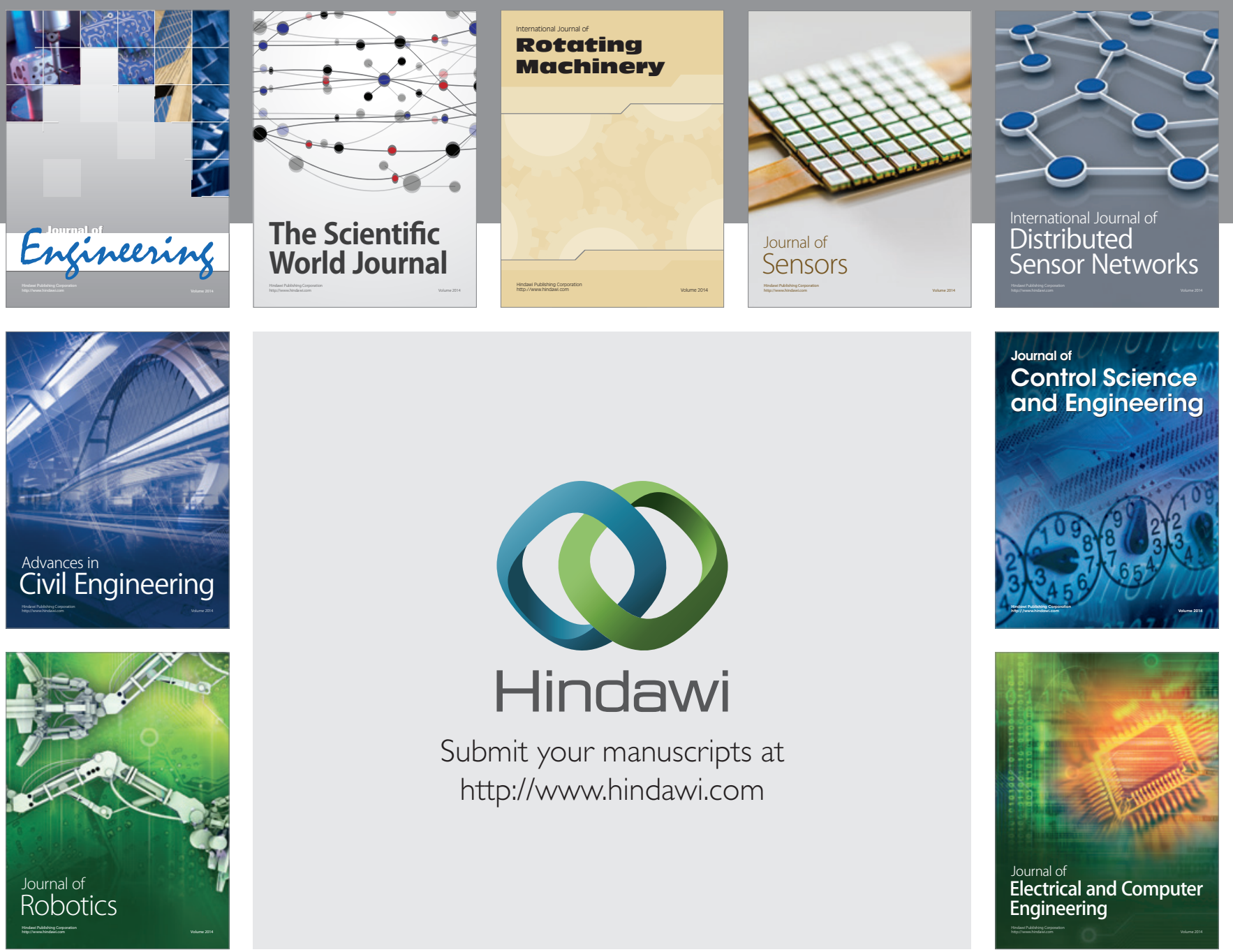

Submit your manuscripts at

http://www.hindawi.com
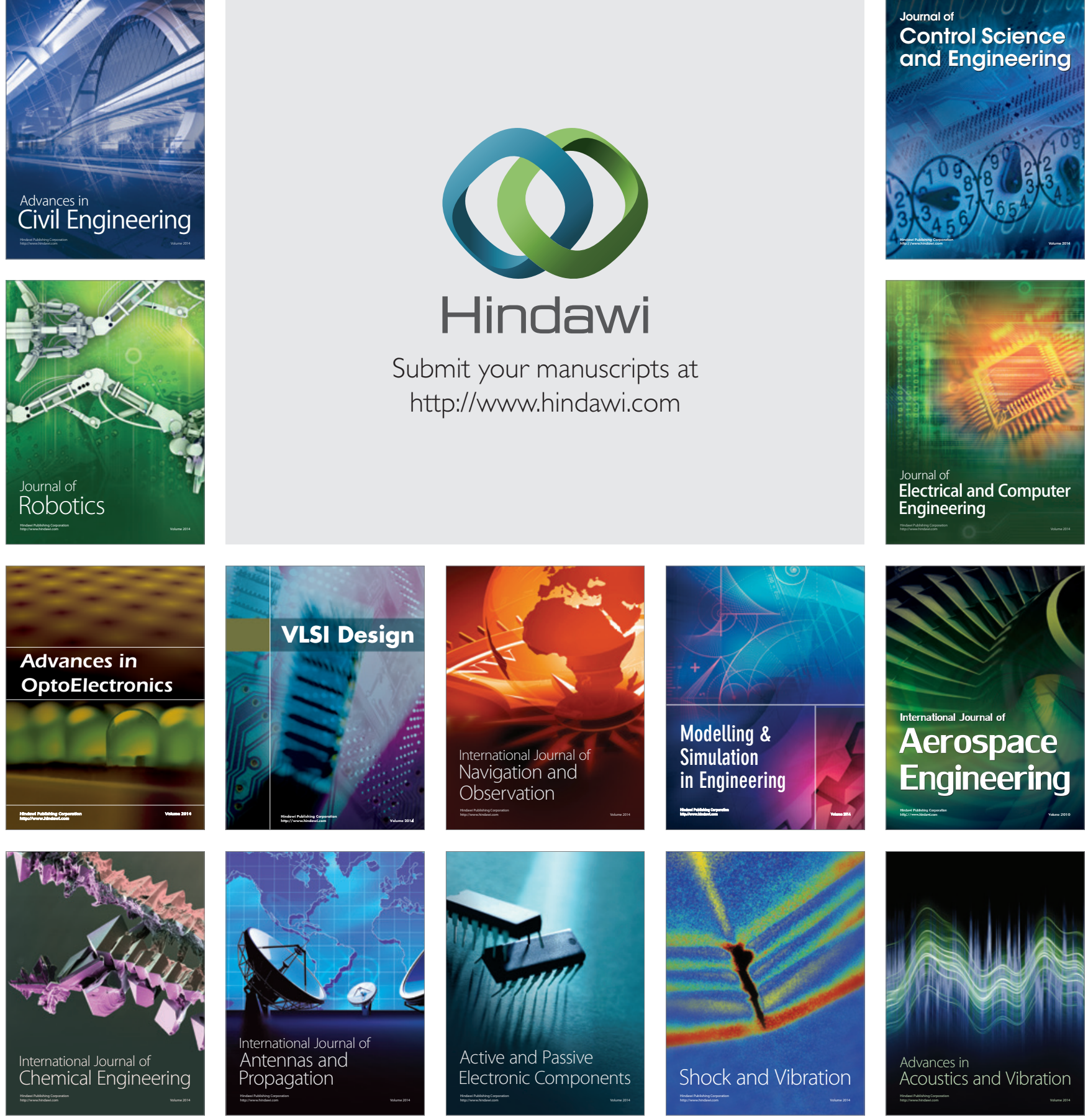